\title{
Squamous Cell Carcinoma over Cutaneous Verrucous Lichen: One Case in Parakou (Benin)
}

\author{
Christiane Koudoukpo ${ }^{*}$, L. V. C. Brun1, F. Akpadjan², B. Dégboé2, N. Agbessi', E. Mensah"1, \\ M. C. Ballé1, F. Malaté1, H. Adégbidi² ${ }^{2}$ F. Atadokpèdé2 \\ ${ }^{1} \mathrm{CHU}$ Borgou/Alibori, Parakou, Benin \\ ${ }^{2} \mathrm{CNHU}$ Hubert Koutoukou Maga, Cotonou, Benin \\ Email: *chkoudoukpo@yahoo.fr
}

How to cite this paper: Koudoukpo, C. Brun, L.V.C., Akpadjan, F., Dégboé, B., Agbessi, N., Mensah, E., Ballé, M.C., Malaté, F., Adégbidi, H. and Atadokpèdé, F. (2019) Squamous Cell Carcinoma over Cutaneous Verrucous Lichen: One Case in Parakou (Benin). Journal of Cosmetics, Dermatological Sciences and Applications, 9, 284-291.

https://doi.org/10.4236/jcdsa.2019.94025

Received: September 29, 2019

Accepted: November 5, 2019

Published: November 8, 2019

Copyright $\odot 2019$ by author(s) and Scientific Research Publishing Inc. This work is licensed under the Creative Commons Attribution-NonCommercial International License (CC BY-NC 4.0). http://creativecommons.org/licenses/by-nc/4.0/ (c) (i) (8) Open Access

\begin{abstract}
Introduction: We report an unusual case of squamous cell carcinoma on a verrucous lichen of chronic evolution taken in charge in Borgou/Alibori UHC in Parakou (Bénin). Observation: A 75-year old Beninese woman with a history of portal hypertension post-viral cirrhosis $C$ treated with negative viral load, had consulted for a large chronic ulceration of the right foot back. The beginning of the symptomatology would go back to about 30 years, marked by lichenified, pruriginous popular lesions; these lesions would initially be treated as eczema and then mycosis by health personnel not specialised in dermatology and multitreated with unspecified topicals. General state was altered. In addition to ulceration, the dermatological examination found plates of hyperpigmented lichen lesion, homogeneous and well limited bilateral and symmetrical topography on the pelvic limbs making difficult to walk. Anatomopathological examination of the biopsy sample straddling the ulceration and its edges suggested a hypertrophic cutaneous lichen associated with keratinizing, infiltrating epidermal carcinoma. The chest-abdominal-pelvic scan showed no metastasis. A complete amputation of the right leg and knee was performed after a psychological interview. The follow-up was marked by an over-infection of the amputation stump by Escherichia coli, which was successfully treated. Healed, she is waiting for orthopedic equipment and possible chemotherapy. Conclusion: This clinical case indicates the need for adequate management of certain potentially precancerous dermatoses, in order to limit the progression to carcinogenic transformation.
\end{abstract}

\section{Keywords}

Cutaneous Verrucous Lichen, Squamous Cell Carcinoma, Amputation, Parakou 


\section{Introduction}

Cutaneous lichen is a chronic inflammatory dermatosis affecting skin, mucous membranes, scalp and nails [1]. Its etiology remains unclear [1]. An association with hepatitis $\mathrm{C}$ is classically described [2]. The carcinogenic transformation of mucous lichen is described in the literature with an incidence of approximately $1.09 \%$ [3]. However only a few cases of carcinomatous transformations on cutaneous lichen are described in the literature [3] [4]. We report a case of squamous cell carcinoma on a verrucous lichen of chronic evolution.

\section{Observation}

A 75-year-old Beninese woman with a history of hypertension with post-viral cirrhosis $\mathrm{C}$ treated with negative viral load is admitted to a dermatological consultation at the UHC Borgou/Alibori (UHC-BA) in Parakou (Benin) April 15th 2019. The pattern was a large ulceration of the back of the right foot that had been developing for 12 years.

In the history, the symptomatology goes back to about 30 years, marked by the appearance of pruriginous papular lesions on the pelvic limbs. She would have previously consulted in two media for her skin lesions and these had been put:

- On the account of mycosis, followed by eczema by nondermatological health care personnel, consulted by the patient from the first symptoms;

- On the other hand for a spell by transliterators.

The multiple prior non-specific therapies instituted were made up of local antimycotic and antipruritic drugs and oral antihistamines. For follow-up in hepato-gastro-enterology, she was treated with Sofosbuvir, Ledipasvir and Ribavirine for 12 weeks with viral load negativity. She is currently on Duphalac and Propanolol, oral. The patient was also reportedly subjected to traditional herbal medicine by local and personal means.

The consultation in the Dermatology-Venerology Department of UHC-B/A was motivated by the persistence for 12 years, from a large ulceration on the back of the right foot, secondary to the incision of a swelling in one of the lesions. The general condition was altered. The dermatological examination revealed:

- From the front of the distal quarter of the leg to the back of the right foot

$\checkmark$ A large, budding, hollowing ulceration in places;

$\checkmark$ A large 25-centimeters oval cupboard, easily bleeding on contact, with raised edges and shredded (Figure 1).

- On the anterior-lateral side of the right leg and knee, achromic macular medallions and closets, represented by erosive lesions with clear boundaries, coexisting with lichenified medallions, non-homogeneous and well-limited hyperpigments (Figure 2).

- On the anterior side of the distal third of the left leg, the presence of lichenified, hyperpigmented, warty-like lesions with achromic-spot areas of varying size with clear boundaries (Figure 3 ). 


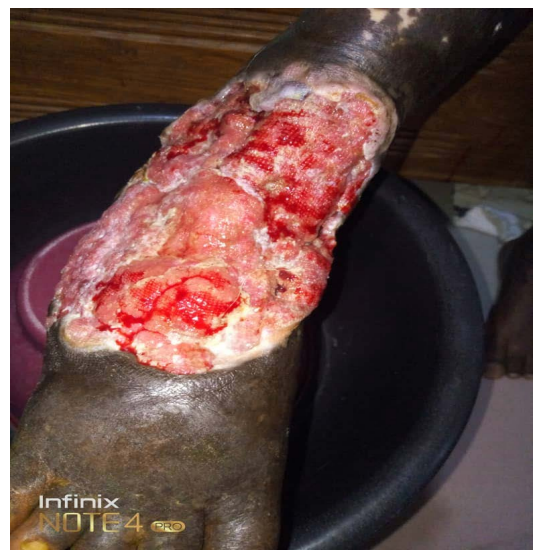

Figure 1. Large, bulging, hollowing ulceration bleeding easily on contact, with raised and jagged edges of the back of the right foot and distal quarter of the right leg (Initial view taken on the first day of consultation in the Dermatology-Venerology Department of UHC-B/A).

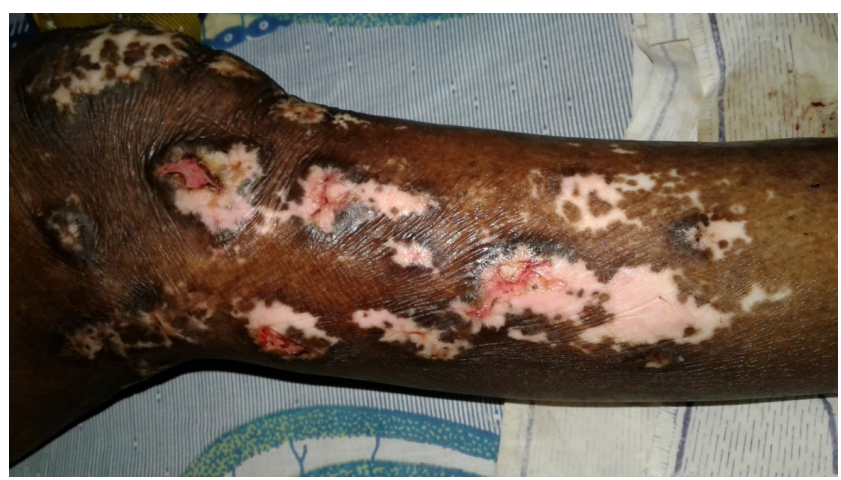

Figure 2. Achromic macular medallions and closets, clear-boundary erosive lesion sites coexisting with well-limited, homogeneous, hyperpigmented lichenified medallions of the antero-lateral side of the right leg and knee (Initial view taken on the first day of consultation in the Dermatology-Venerology Department of UHC-B/A).

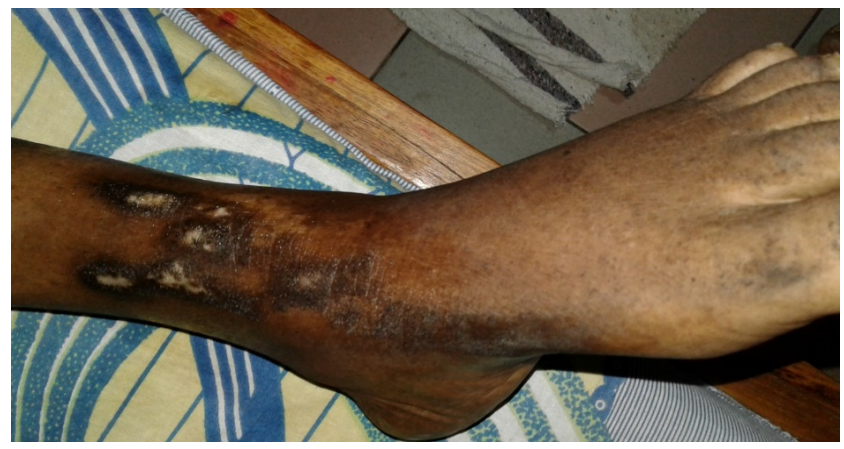

Figure 3. Hyperpigmented lichenified cupboards with warty appearance, with some achromic zones with clear boundaries of the front side of the 1/3 distal left leg (Initial view taken on the first day of consultation in the Dermatology-Venerology Department of UHC-B/A).

Also, there was no satellite adenopathy. The clinical diagnosis was in favour of a warty cutaneous lichen. 
At the para-clinical level:

- Liver transaminases were normal with ALAT at 34 IU/l and ASAT 29 IU/l;

- Chest-abdominal-pelvic scan showed no evidence of metastasis;

- Anatomopathological examination of the biopsy sample straddling the ulceration and its edges concluded that hypertrophic cutaneous lichen (Figure 4(a)) was associated with infiltrating keratinizing epidermal carcinoma (Figure 4(b)).

The positive diagnosis of squamous cell carcinoma on a warty cutaneous lichen was retained.

At the therapeutic and evolutionary levels:

- The patient underwent an amputation after a preoperative psychological interview, with the entire leg and right knee, to ensure a healthy skin surgical procedure;

- Vitamin A ointment was applied in the mornings to the nonerosive lichen plates and Clobetasol Proprionate ointment in the evenings;

- Postoperative psychological management has been instituted to prevent the development of phantom limb syndrome, as well as systematic physiotherapy;

- Surgical follow-up was complicated on the eighth day of an infection of the operative stump with Escherichia coli, resulting in the association of dressings and 12-hour injections of $1 \mathrm{~g}$ Ceftriaxone venously for 10 days;

- Complete scarring of the surgical wound was obtained after three weeks in hospital (Figure 5);

- The patient now continues to perform functional rehabilitation with two canes while waiting for her equipment by installing a right leg prosthesis and possible subsequent chemotherapy in case follow-up from the checkup will have revealed metastasis.

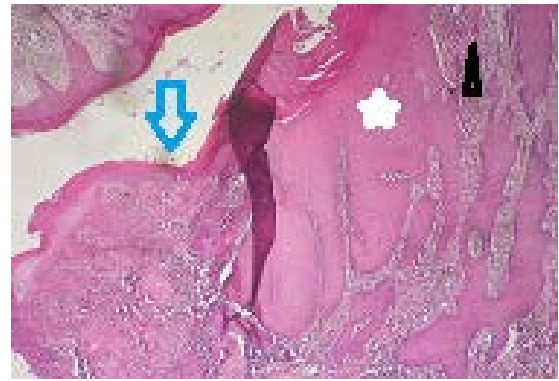

(a)

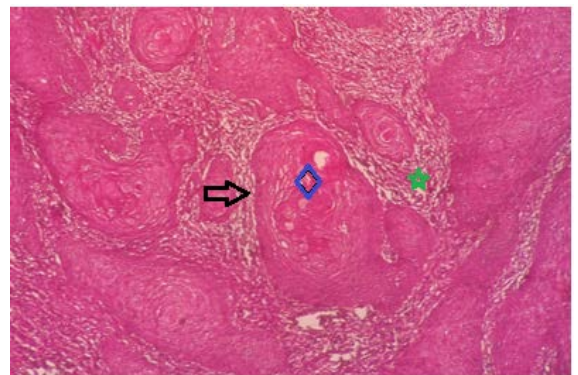

(b)

Figure 4. (a) Hypertrophic lichen (Hematoxylin and Eosin $\times 4$ ). Skin tissue where hyperplastic epitheliomatous lesions (white star) occur in places. Presence of orthokeratosis hyperkeratosis (blue arrow), irregular acanthosis with jagged appearance of interpapillary buds. Presence of inflammatory infiltrate of the subcutaneous epidermis (black triangle) made of mild to moderate perivascular lymphocytes; (b) Invasive keratinizing squamous cell carcinoma (Hematoxylin and Eosin $\times 10$ ). Tumour clusters and casings (black arrow) more or less interconnected. Presence of a maturing gradient from the periphery to the center of the clusters, seat of horny globes (blue diamond). The stroma is fibroinflammatory rich in lymphocytes (green star). 


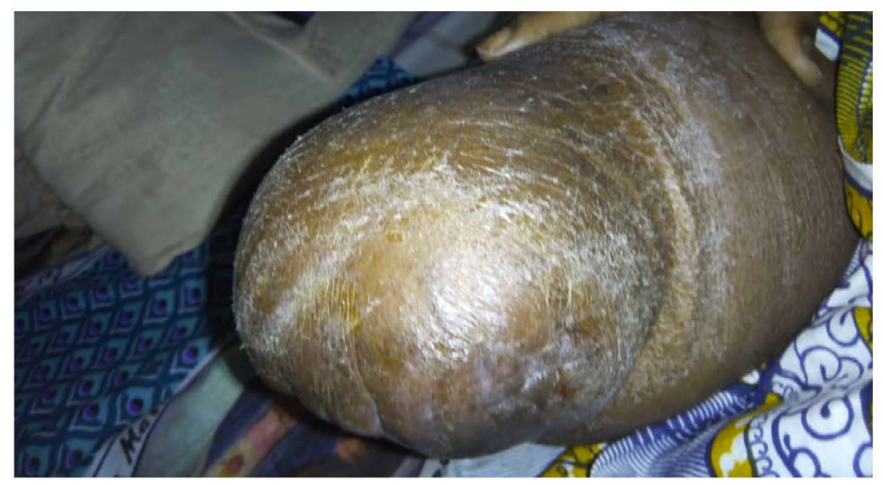

Figure 5. Complete scarring of the amputation stump (View taken one month after the surgical operation).

\section{Discussion}

Carcinomatous transformation of cutaneous lichen is described but remains unusual. The dominant location of that transformation was the pelvic limb in $87 \%$ of cases according to Sigurgeirsson et al. [5] and it is often a leg injury in two thirds of cases, especially to the distal third as was found in our patient. An association between viral hepatitis $\mathrm{C}$ and cutaneous lichen has been described in the literature by some authors [2] [6]. Others cite it in dermatological manifestations associated with viral hepatitis C [7] [8]. This association was found in our patient. Squamous cell carcinomas refer to early malignant epithelial tumours that express squamous cell differentiation; they are distinct from basal cell carcinomas [9]. They can occur de novo or more often indicate the development of lesions considered as non-invasive precursors such as actinic keratosis and Bowen's disease [9]. TNM classification of the American Joint Committee on Cancer [10] allows us to enter our case in stage 3 , given this important criterion of the size of the lesion far greater than $4 \mathrm{~cm}$ of large diameter. Cutaneous lichen is a chronic inflammatory dermatosis that stimulates cell renewal; increased free radicals, increased growth factors and accelerated cell multiplication, according to some authors [11] [12], carcinogenesis. Rare cases of carcinomatous transformation of cutaneous lichen described in the literature [13] [14] [15] [16] [17] despite a significant prevalence of this condition, do not lead to a possible association, "cutaneous lichen and risk of carcinomatous transformation" Sigurgeivsson et al. [5] concluded that cutaneous lichen was not a precancerous dermatosis. Some authors make a link between occurrence of skin squamous cell carcinoma and certain occupations including ultraviolet radiation occupations and exposure to polycyclic aromatic hydrocarbons [18] [19].

Diagnostic wandering for several years that may contribute to the progression to eczematization and impetiginization in our patient, does not identify potential iatrogenic risk factors for carcinogenic transformation. The ideal would be to refer any dermatosis to the specialist in order to establish an accurate diagnosis and regular follow-up of the patient. Evolution of this pathology for many years, in a context of relative immunodepression related to the treatment of eczema 
and/or lichen (by corticosteroids). These are all parameters that can promote carcinomatous transformation in our patient. Some factors appear to be poor prognosis, such as erosive or hypertrophic damage, palmar and plantar extremities that are exposed to repetitive trauma [5]. Our patient with erosive and hypertrophic wart-like lesions in places should have been followed by a dermatologist on a regular basis. Regular monitoring with biopsy samples for anatomopathological examination at the slightest clinical doubt is necessary in these particular forms of cutaneous lichen. Therapeutic education in this case must be carried out from the beginning of the disease, as carcinomatous transformation can occur early. It is clear from the analysis of this clinical case that all medical personnel, whatever their level, must know their limits in the exercise of their duties. It is also necessary to remind the population not to rely on phytotherapy especially in Africa, a source of renal complication, eczematization or impetiginization in case of local use. Despite a few rare cases of carcinogenic transformation of cutaneous lichen described in the literature [13] [14] [15] [16] [17], it is not a precancerous dermatosis. Nevertheless some clinical forms of cutaneous lichen including morphological (verrucous and erosive forms) and topographical (end forms) deserve special monitoring because factors of poor prognosis in carcinogenic transformation [5]. Treatment of choice for skin squamous cell carcinoma is primarily surgical [20]. The objective is to obtain a complete removal of the tumor with well recommended margins depending on the prognosis. In the case of skin squamous cell carcinoma with little differentiation, a minimum margin of 6 to $10 \mathrm{~mm}$ is proposed [20]. The amputation to the distal quarter of the right thigh in our patient in the interest of a healthy skin procedure also justifies the margin of exeresis proposed and respected, due to the extension of other lichen plates to the right knee. Better management of cutaneous lichen in our patient would have prevented the progression to this carcinogenic transformation.

\section{Conclusion}

The occurrence of squamous cell carcinoma on a warty cutaneous lichen is an unusual clinical fact. Early and correct management of potentially precancerous dermatoses should prevent such events.

\section{Consent}

The patient gave her informed consent for the publication of this case.

\section{Conflicts of Interest}

The authors declare no conflict of interest.

\section{References}

[1] Le Cleach, L. and Chosidow, O. (2012) Clinical Practice. Lichen Planus. The New England Journal of Medicine, 366, 723-732. 
https://doi.org/10.1056/NEJMcp1103641

[2] Strak, S.K., Al-Hamdi, K.I. and Alabbood, M.H. (2015) A Study of Lichen Planus and Its Association with Hepatitis C Infection. Journal of Taibah University Medical Sciences, 10, 222-226. https://doi.org/10.1016/j.jtumed.2014.08.001

[3] Fitzpatrick, S.G., Hirsch, S.A. and Gordon, S.C. (2014) The Malignant Transformation of Oral Lichen Planus and Oral Lichenoid Lesions: A Systematic Review. The Journal of the American Dental Association, 145, 45-56. https://doi.org/10.14219/jada.2013.10

[4] Ali, N.M., Bhat, R. and Rao, S.B. (2015) Concurrent Presentation of Erythrodermic Lichen Planus and Squamous Cell Carcinoma: Coincidence or Malignant Transformation? Indian Journal of Dermatology, 60, 457-460. https://doi.org/10.4103/0019-5154.164355

[5] Sigurgeirsson, B. and Lindelöf, B. (1991) Lichen Planus and Malignancy. An Epidemiologic Study of 2071 Patients and a Review of Literature. Archives of Dermatology, 127, 1684-1688. https://doi.org/10.1001/archderm.1991.01680100084009

[6] Raharolahy, O., Andrianarison, M., Ranaivo, I.M., Sendrasoa, F.A., Ramarozatovo, L.S. and Rapelanoro Rabenja, F. (2016) Manifestations cutanées inhabituelles au cours de l'hépatite virale C. Annales de Dermatologie et de Vénéréologie, 143, 15-16. https://doi.org/10.1016/S0151-9638(16)30117-X

[7] Kchir, H., Dabbedi, H., Mahfoudhi, M., Essid, M., Ben Jeddi, H., Chaabouni, H., et al. (2015) Manifestations dermatologiques associées au virus de l'hépatite C. La Revue de Médecine Interne, 36, 102. https://doi.org/10.1016/j.revmed.2015.03.076

[8] Dupond, A.S. (2014) Lichen plan et dermatoses lichénoïdes. Traité de IEMC, 9, $1-11$.

[9] Burton, K.A., Ashack, K.A. and Khachemoune, A. (2016) Cutaneous Squamous Cell Carcinoma: A Review of High-Risk and Metastatic Disease. American Journal of Clinical Dermatology, 17, 491-508. https://doi.org/10.1007/s40257-016-0207-3

[10] Farasat, S., Yu, S.S., Neel, V.A., Nehal, K.S., Lardaro, T., Mihm, M.C., et al. (2011) A New American Joint Committee on Cancer Staging System for Cutaneous Squamous Cell Carcinoma: Creation and Rational for Inclusion of Tumor Characteristics. Journal of the American Academy of Dermatology, 64, 1051-1059. https://doi.org/10.1016/j.jaad.2010.08.033

[11] Yao, M., Brummer, G., Acevedo, D. and Cheng, N. (2016) Cytokine Regulation of Metastasis and Tumorigenicity. Advances in Cancer Research, 132, 265-367. https://doi.org/10.1016/bs.acr.2016.05.005

[12] Reich-Schupke, S., Doerler, M., Wollina, U., Dissemond, J., Horn, T., Strölin, A., et al. (2015) Squamous Cell Carcinomas in Chronic Venous Leg Ulcers. Data of the German Marjolin Registry and Review. Journal der Deutschen Dermatologischen Gesellschaft, 13, 1006-1013. https://doi.org/10.1111/ddg.12649

[13] Oshi, R. and Durve, U. (2007) Squamous Cell Carcinoma in Hypertrophic Lichen Planus. Indian Journal of Dermatology, Venereology and Leprology, 13, 54-55. https://doi.org/10.4103/0378-6323.30658

[14] Olawoye, O.A., Michael, A.I. and Oluwasola, O.A. (2013) Marjolin's Ulcer Arising from Cutaneous Lichen Planus. East and Central African Journal of Surgery, 18, 164-167.

[15] Shetty, R., Lamba, S., Gulur, A., Patel, S. and Kumar Gupta, A. (2013) Carcinoma in Cutaneous Lichen Planus. Nasza Dermatologia Online. Our Dermatology Online, 4, 75-77. https://doi.org/10.7241/ourd.20131.14 
[16] Thakur, B.K., Verma, S. and Raphael, V. (2015) Verrucous Carcinoma Developing in a Long Standing Case of Ulcerative Lichen Planus of Sole: A Rare Case Report. Journal of the European Academy of Dermatology and Venereology, 29, 399-401. https://doi.org/10.1111/jdv.12406

[17] Tong, L.X., Weinstock, M.J., Drews, R., Sheikine, Y. and Kim, C.C. (2015) Widely Metastatic Squamous Cell Carcinoma Originating from Malignant Transformation of Hypertrophic Lichen Planus in a 24-Year-Old Woman: Case Report and Review of the Literature. Pediatric Dermatology, 32, 98-101.

https://doi.org/10.1111/pde.12549

[18] Alfonso, J.H., Martinsen, J.I., Pukkala, E., Weiderpass, E., Tryggvadottir, L., Nordby, K.-C., et al. (2016) Occupation and Relative Risk of Cutaneous Squamous Cell Carcinoma: A 45-Year Follow-Up Study in 4 Nordic Countries. Journal of the American Academy of Dermatology, 75, 548-555.

https://doi.org/10.1016/j.jaad.2016.03.033

[19] Dervault, A.M., Secretan, B., Guinot, C., Bazex, J., Donadieu, J., Doré, et al. (2005) Ultraviolets-Etats des connaissances sur l'exposition et les risques sanitaires. Afsse InVs Afssaps, 44-45.

[20] Bonerandi, J.J., Beauvillain, C., Caquant, L., Chassagne, J.F., Chaussade, V., Clavère, P., et al. (2011) Guidelines for the Diagnosis and Treatment of Cutaneous Squamous Cell Carcinoma and Precursor Lesions. Journal of the European Academy of Dermatology and Venereology, 25, 1-51. https://doi.org/10.1111/j.1468-3083.2011.04296.x 